\title{
Palacios y mansiones de la España judía
}

\author{
ana maria lópez Álvarez * \\ Ma LUISA MENÉNDEZ ROBLES **
}

Cuando estudiamos la arqueología de los judíos españoles siempre nos sorprende porque las noticias que tenemos se refieren sobre todo a sinagogas, pero rara vez a otro tipo de construcciones, baños, edificios comunales (hospitales, hornos, carnicerías, escuelas, tribunales, palacios, etc.). Por lo que se refiere a estos últimos o a grandes mansiones, tuvo que haberlos, ya que en la corte destacaron importantes personajes judios tanto en Al-Andalus como en la España cristiana tales como Hasdai ibn Saprut, Samuel ibn Nagrella y su familia, Isaac de la Maleha, Samuel haLeví... y tantos otros que ocuparon un papel destacado en la política o en la cultura.

Los restos arqueológicos son escasos y la documentación en general sólo nos habla de casas, pequeñas posesiones agrícolas y poco más. No tenemos por tanto noticias de grandes propiedades o palacios. Sólo nos han llegado noticias y restos documentales o arqueológicos de dos que fueron destruidos antes de la expulsión de los judíos de España. Estos edificios a los que nos referimos son: el palacio de Yehosef ibn Nagrella, consejero que fue como su padre Samuel, del rey zirí de Granada, Baddis y el que fue de Dn. Samuel Leví, consejero y tesorero del rey don Pedrol de Castilla.

Por lo que respecta al palacio granadino las noticias que tenemos son sobre todo literarias y algún resto arqueológico.

Así, entre las primeras, están las memorias personales escritas en su exilio de Marruecos por el último rey beréber de Granada, Abd Allāh (1073-

* Museo Sefardi. Toledo.

** Museo Serfardí. Toledo. 
1090), nieto y sucesor del rey Bàdis ibn Habbūs (1030-1078), que hace prolongadas referencias a Samuel y Yehosef ibn Nagrella, los dos cancilleres judíos, aunque cuando se refiere a este último lo hace siempre con resentimiento aludiendo a la situación que se creó en la ciudad contra Yehosef y que desembocó en los disturbios que acabaron con la vida de éste: «Mientras tanto se profundizó la brecha entre el judío y la población (de Granada), y aumentaron los disturbios. El judio, temeroso de la gente, cambió su domicilio (temporalmente) a la Alcazaba, hasta que se realizaron sus expectativas. Con ello se manejó a los habitantes (de Granada), así como por su edificación de la fortaleza de la Alhambra (al-in al amr) (sic), donde el se proponía residir con su familia, cuando ibn um di hubiera entrado en Granada, una vez estabilizada la situación»'

No podemos dudar que con el poder de que gozaba Yehosef no pudiese construirse una mansión fortificada sobre la colina de la Alhambra. Que tal edificio tuviera un carácter monumental puede deducirse de otro pasaje de la crónica real, donde un miembro del consejo, para influenciar al rey sobre su canciller judío, describe el edificio de Yehosef como "mejor que vuestro propio castillo" ${ }^{2}$. El castillo real al que se hace referencia es Al-Qasaba (al-) Qadima (actualmente casi destruido) que se hallaba situado en la colina del Albaicín frente a la de la Alhambra. Torres Balbás ${ }^{3}$ indica que: "el judío Samuel ibn Nagrila... hizo construir la fortaleza de la Alhambra para refugiarse en ella con su familia, hasta tanto que se restableciera la calma, cuando el rey de Almería al-Mu'tasim, con el cual parece que estaba de acuerdo, penetrarse en Granada y se hiciera dueño de la ciudad".

No existe ninguna razón para dudar de la referencia de Abd-Allāh a la construcción de la Alhambra, puesto que tales hechos deben haber sido del dominio común de aquel tiempo. Por otro lado las Memorias de AbdAllāh están consideradas como una de las fuentes más fiables de la historia zirí. Tampoco hay que dudar sobre el significado que se le debe dar a "Alhambra», que siempre ha sido el nombre dado a la misma colina, que aparece ya en las fuentes árabes, desde final del siglo xl; como sucede con la colina del Albaicín y el Castillo de los reyes zaríes que se conoció como "Palacio de Bādís".

Levi Provencal, E. y García Gómez, Emilio, El siglo xi en $1^{a}$ persona. Las «memorias» de Ábd Allah, último rey ziri de Granada, destronado por los almorávides (1090). Traducidas por.... pág. 131-132.

$=$ Levi Provencal, E.,... op. cit., pág. 119.

3 Torres Balbas, L., "La Alhambra de Granada antes del siglo XIII», Al-Andalus, vol V, (1940), págs. 154-174. 


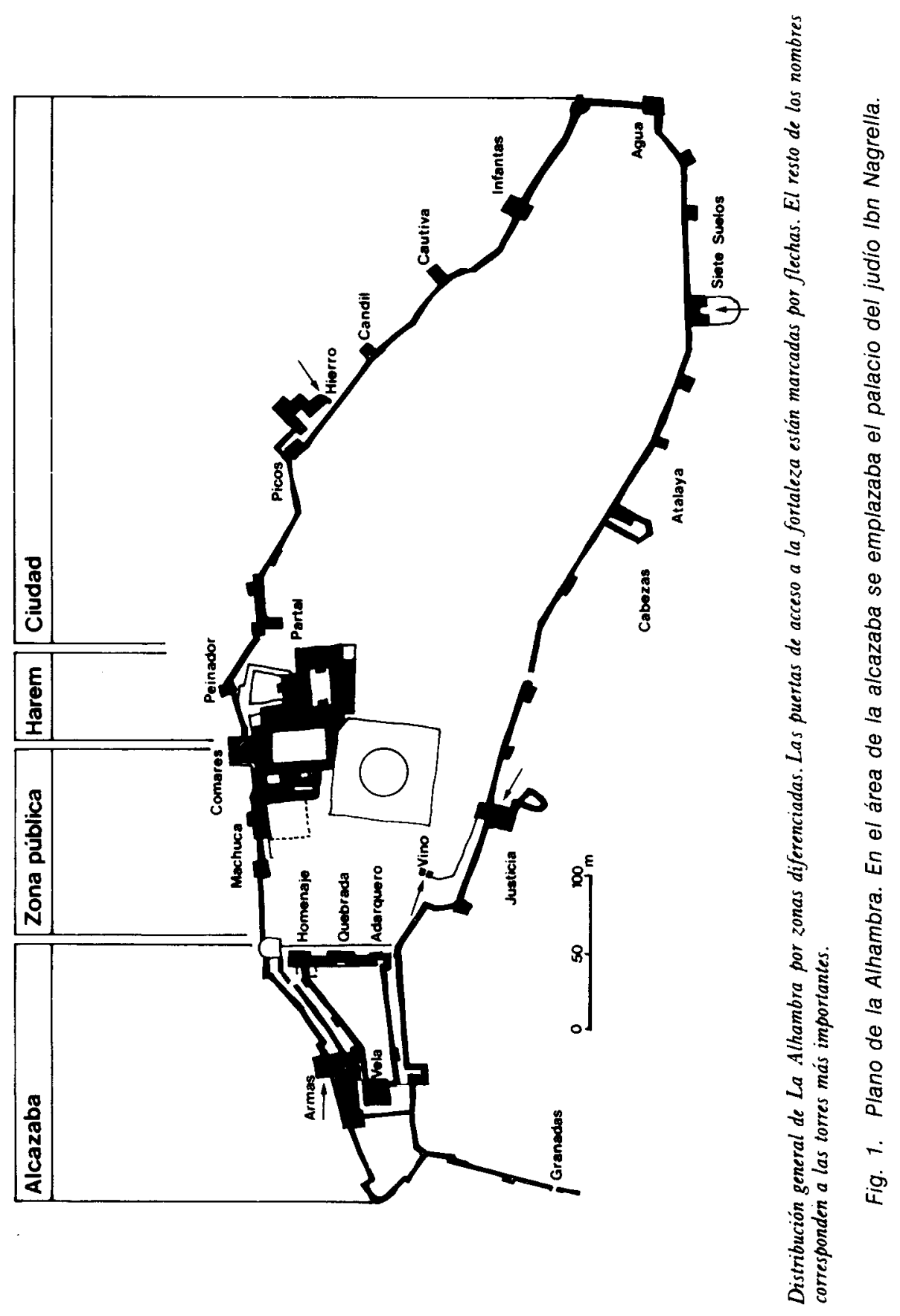


El problema que surge de tal testimonio es que se puede y se debe buscar los rastros de lo que ha podido quedar dentro de las actuales edificaciones de la Alhambra de los restos del palacio de Ibn Nagrella y de viviendas o mansiones de otros personajes judíos según recogen las citadas memorias de Abdallah ${ }^{4}$ quienes, como en el caso del palacio de Samuel Leví que estudiaremos después, reunían én un mismo lugar vivienda y áreas de trabajo. Alguna luz arrojan las excavaciones ya realizadas, y las noticias que podemos encontrar en la literatura de la época y que puedan ampliar la información dada por Abd-Allāh.

Buscando otros testimonios árabes, hay que recordar la animadversión que tuvo Ibn Hazm, el gran poeta cordobés hacia Samuel ibn Nagrella, y que contagió a Abū Ișhạa "el faqih de Elviar». Parece que se desarrolló una creciente enemistad en amplios círculos de la España musulmana contra los Nagrella y los judíos en general. Por su parte Abú Ișhãq envió un poema a Granada para atacar a Yehosef ibn Nagrella, donde en un paraje en que da una descripción de la arrogancia de los judios de Granada, se refiere concretamente a Yehosef ibn Nagrella diciendo:

Este imitador suyo se ha revestido su mansión con piedras y hace que fluyan hacia allí la más pura fuente.

Nuestras necesidades están a su cuidado y debemos aguardar a su puerta... ${ }^{5}$.

Claramente hace referencia Abū Ișhāq en estas líneas a la actividad constructora de Yehosef ibn Nagrella. El poeta cita como ejemplo de las extravagancias de Ibn Nagrella su gusto por los materiales valiosos, y, peor aún, el abuso de poder al desviar «la mejor fuente hacia su mansión». Parece referirse con esto último a que tal aprovisionamiento de agua no sería únicamente para los servicios normales de la casa sino que, como en los castillos árabes contemporáneos servirá para regar jardines.

Abū Ișhāq no menciona particularmente la Alhambra por su nombre, pudiéndose aplicar tal noticia a otra mansión localizada en Granada, aunque el estilo polémico de tal referencia, unida a la de las memorias de

4 Levi Provençal, E. y García Gómez, E., op. cit. Tenemos referencia de otro judío Abū-IRabì ibn la-Matūnī, que era quien cobraba las rentas del patrimonio real, quien también construyó en el mismo lugar: "Cuando ordené la construcción del muro contiguo a la Alhambra [alHamrā], movido a ello por acontecimientos tan notorios que me relevan de comentarios, tuvimos la buena fortuna de que los albañiles encontraron, al hacer los cimientos, una orza llena de oro... Como sobre aquellos cimientos se levantó en otro tiempo la casa del judio Abü-l-Rabi, que fue tesorero bajo el gobierno de mi abuelo...

5 Bargebuhr, Frederick, P., The Alhambra. A cycle of Studies on Eleventh Century in Morish Spain. Berlín 1968, pág. 93. 
Ab-Allāh parece que ambas están motivadas por la construcción de la Alhambra por Ibn Nagrella. El recubrimiento de piedra del poema, puede referirse tanto al suelo como a las paredes.

Las memorias y el poema se apoyan mutuamente, y no parece existir razón para dudar del hecho de que Yehosef ibn Nagrella llevó a cabo lujosas construcciones en la colina de la Alhambra. Posiblemente éstas se situaron en la colina de la al-Sabika donde algunos restos de la época de ibn Nagrella se han conservado ${ }^{6}$.

Dado que conocemos por fuente judías que Yehosef al igual que su padre, se rodeó de un círculo de estudiosos y poetas para magnificar su corte, es lógico suponer que encontremos alguna referencia a alguna fuente judía en las construcciones que realizó, y de hecho así es. El poema de Ibn Gabirol que vamos a examinar a continuación se suma a las noticias de las edificaciones judías del siglo XI en Granada. Nacido en Málaga, procede de una familia que, al igual que los Ibn Nagrella, tuvo que emigrar de Córdoba, de ahí su típica orientación intelectual de tipo liberal como estos. De este gran poeta y pensador conservamos en su diwán de poemas profanos un poema que nos interesa particularmente por el tema que estamos abordando, es un poema descriptivo que fue primeramente publicado por Schirman en una colección, en 1941 reproducido posteriormente. Recogemos la edición Elena Romero ${ }^{7}$.

a) Introdución en que se invita al lector, en unos versos calcados del Cantar de los Cantares.

Ven, amigo, y amigo de los astros;

Ven conmigo a dormir en las aldeas,

que ya pasó el invierno y se oye en nuestra tierra

el clamor de zorzales y de tórtolas....

b) Descripción de un palacio fortificado, levantado de acuerdo con un plan muy meditado, construido con materiales selectos y de belleza impresionante; aparte del edificio, con sus torres, sus innumerables puertas y una extraordinaria cúpula, se encuentra también una gran pila comparable al mar de bronce de Salomón, aunque no esté sostenida por bueyes sino por leones que rugen como si fueran a arrojarse sobre alguna presa, pero cuyos vientres son como fuentes que arrojan fuera el agua como chorros a través de sus bocas ${ }^{8}$.

6 Bermúdez Pareja, Jesús, "La fuente de los Leones", Cuadernos de la Alhambra, 3. Granada 1967, pág. 23.

Romero, Elena, Selomó ibn Gabirol. Poesía secular... Madrid 1978, págs. 175-179.

8 Bargebuhr, Frederick P., op. cit. Para un estudio más completo del significado de estos 
Vaguemos a la sombra de las parras dejándonos vencer por el deseo

de contemplar imágenes radiantes

en un palacio erguido sobre sus derredores.

De ricas piedras hecho, que fue planificado con justeza,

sus muros y cimientos de fuertes torreones.

Se abre una explanada en su contorno:

parterres de narcisos sus patios engalanan;

sus cámaras, que han sido construidas

y ornadas de atauriques calados y cerrados,

están pavimentadas de mármol y de pórfido

y no puedo contar los pórticos que tiene...

Hay un copioso estanque que semeja

al mar de Salomón

pero que no descansa sobre toros;

tal es el ademán de los leones,

que están sobre el brocal, cual si estuvieran

rugiendo los cachorros por la presa...

c) Se describe un magnífico jardín que pertenece a tal palacio.

Y junto a los canales, hincadas, corzas huecas

para que el agua sea trasvasada

y rociar con ella en los parterres

las plantas y asperjar los juncos de aguas puras

$y$ el huerto de los mirtos con ellas abrevarlo;

y siendo como nubes, salpican un ramaje

fragante, con aromas de esencias, cual si fuera

de mirras incensado.

Las aves en las frondas gorjean y se asoman

por entre los cogollos de las palmas.

De nardos y alcanfores, capullos deliciosos

y frescos como lirios...

d) Todo ello está en consonancia con su dueño, un gran príncipe consejero de reyes que lo han levantado como a su rey, y a quien adornan las mejores cualidades.

Y cuando sobre todos el sol se enaltecía, le constesté: iSilencio!, no cruces los linderos y alaba al poderoso que te ha entenebrecido con una luz excelsa entre los luminares.

animales consultar en parte II del libro el capitulo dedicado al patio de los leones, págs. 106182. 
Que el halo de los reyes se inclina en su presencia

y de sus cualidades los príncipes carecen

Por él todos los reyes se gobiernan;

los nobles y los príncipes en él buscan consejo

como a su rey lo alzaron.... ${ }^{9}$.

Como vemos al poema se mueve dentro de los géneros típicamente árabes: la descripción (wasf) y el encomio palaciego (madih).

Varias preguntas surgen en torno a este poema tan singular: ¿a quién iba dirigido?, ¿qué edificio o palacio se describe en tal poema?

Ante todo hay que suponer que tal poema tuvo que ser compuesto para alguien capaz de leer y entender hebreo, sin duda algún judío, más aún, un judio instruido que captase las alusiones bíblicas que se dan a lo largo del poema, y que estuviese interesado en este género de poesía hebrea profana con sus nuevos esquemas y mentalidad.

Por otra parte la descripción que se hace de imágenes esculpidas (leones), supone un talante liberal en cuanto a la interpretación de la prohibición expresa judía de prescindir de figuraciones. Esto sucedía en la élite intelectual del grupo cordobés. En la historia de los judíos de España de este periodo (siglo XI) sólamente nos encontramos con los Nagrella, padre e hijos, a quienes se pueda dirigir tal clase de poema, y que pudiesen ser los constructores de tal castillo a la par que convenirles los títulos de "consejeros de reyes", y otros, siendo además gente culta y muy instruida.

En cuanto al edificio, el palacio fortaleza, recordemos que dice de él, entre otras cosas, que está como situado sobre una colina «elevado sobre lo que está a su alrededor"; que está "fortificado con torres"; y que es grande: "no pudo contar sus muchas puertas". Que tiene extensos jardines y un patio de arrayanes. Dedica una extraordinaria alabanza a sus fuentes, entre ellas a una fuente que tiene un grupo de leones alrededor de su base sosteniendo una taza que recuerda "el mar de bronce» de Salomón; estos animales están perforados y arrojan agua por su boca. Hay canales de agua, así como ciervos que arrojan agua a tal altura como las copas de los árboles.

Todas estas particularidades del poema de ibn Gabirol convergiendo con los testimonios árabes antes citados hacen que Bargeburhr ${ }^{10}$ defienda

9 Romero Castello, Elena, Selomo ibn Gabirol. Poesia secular. Prólogo Dan Pagis. Selección, Traducción y Notas Elena Romero. Edición bilingüe. Madrid 1978, [Es el poema $n^{\circ} 57$, titulado El palacio y el jardín, págs. 174-179].

${ }_{10}$ Bargebuha, Frederick P., op. cit. 


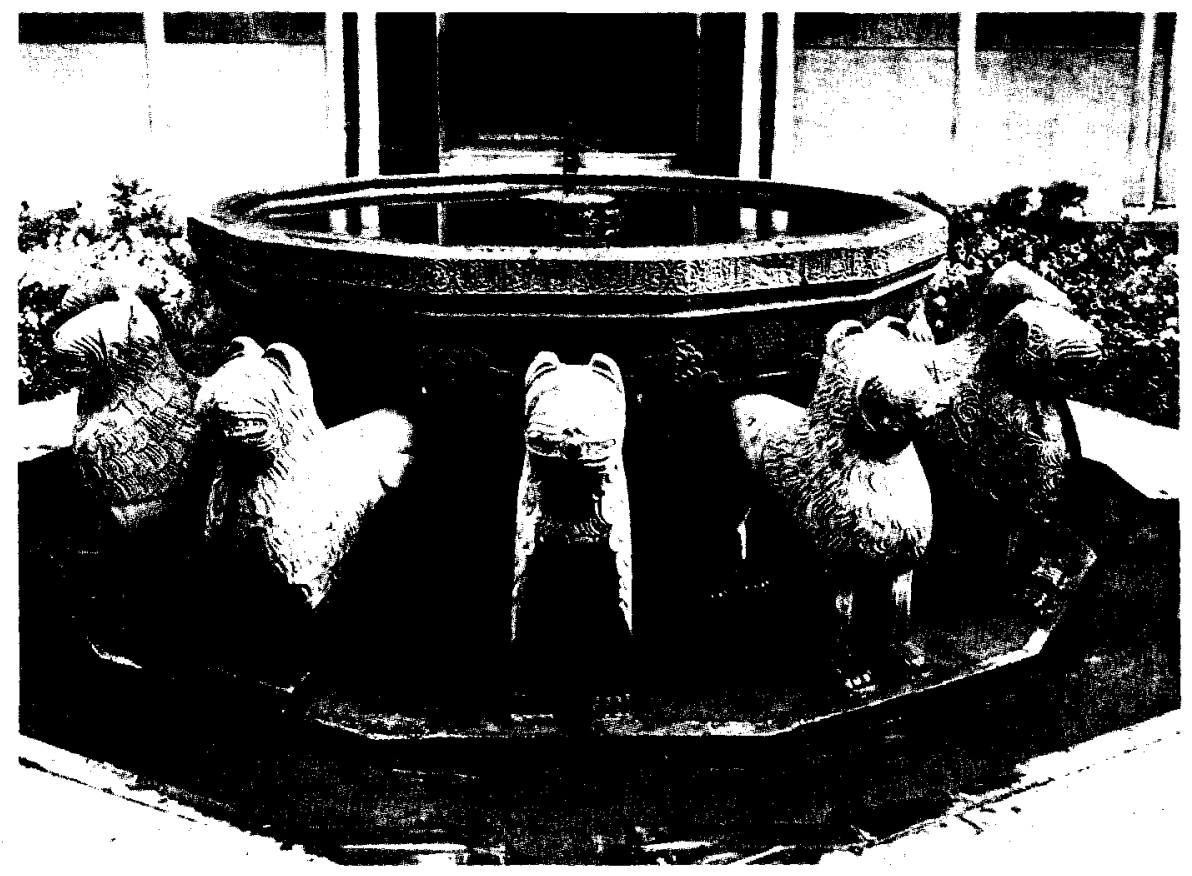

Fig. 2. Fuente de los Leones.

la tesis de que en conjunto nos señalan a un palacio-fortaleza que se construyó un judío eminente en su época, Yehosef ibn Nagrella, en la colina de la Alhambra, del que son testimonios los restos del siglo XI en el actual edificio de la Alhambra levantado en los siglos XIII y XIV. A continuación detallamos cuales pueden ser tales restos que pudieron pertenecer a las edificaciones hechas por ibn Nagrella.

Si los testimonios literarios son amplios, no ocurre lo mismo con los restos arqueológicos. El poema de Ibn Gabirol describe con detalle, como hemos visto, un palacio fortificado construido con materiales preciosos dotado de una cúpula y una fuente de leones que suscitan la admiración del poeta. Entre los restos de la actual Alhambra donde es más lógico que se encuentren los vestigios de tal construcción. Los cimientos y las partes inferiores de casi toda la Alcazaba actual son obra de fábrica típica del siglo XI similar constructivamente a los restos más antiguos de la alcazaba de Málaga. Conocemos más hechos de la Alhambra de este período por las memorias del rey Abd Allah, último rey zirí, que volvió a fortificar Granada. 


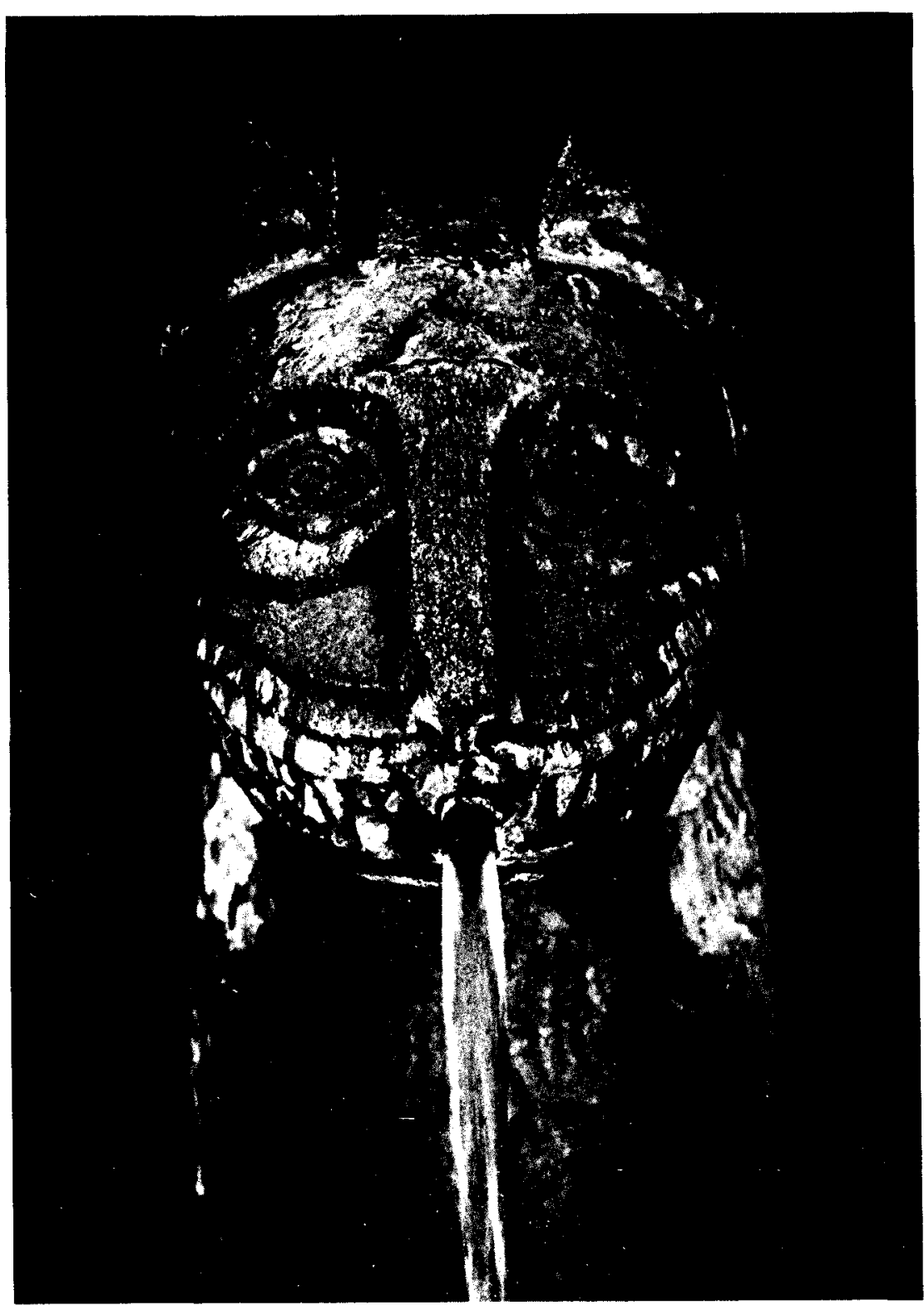

Fig. 3. Detalle. 


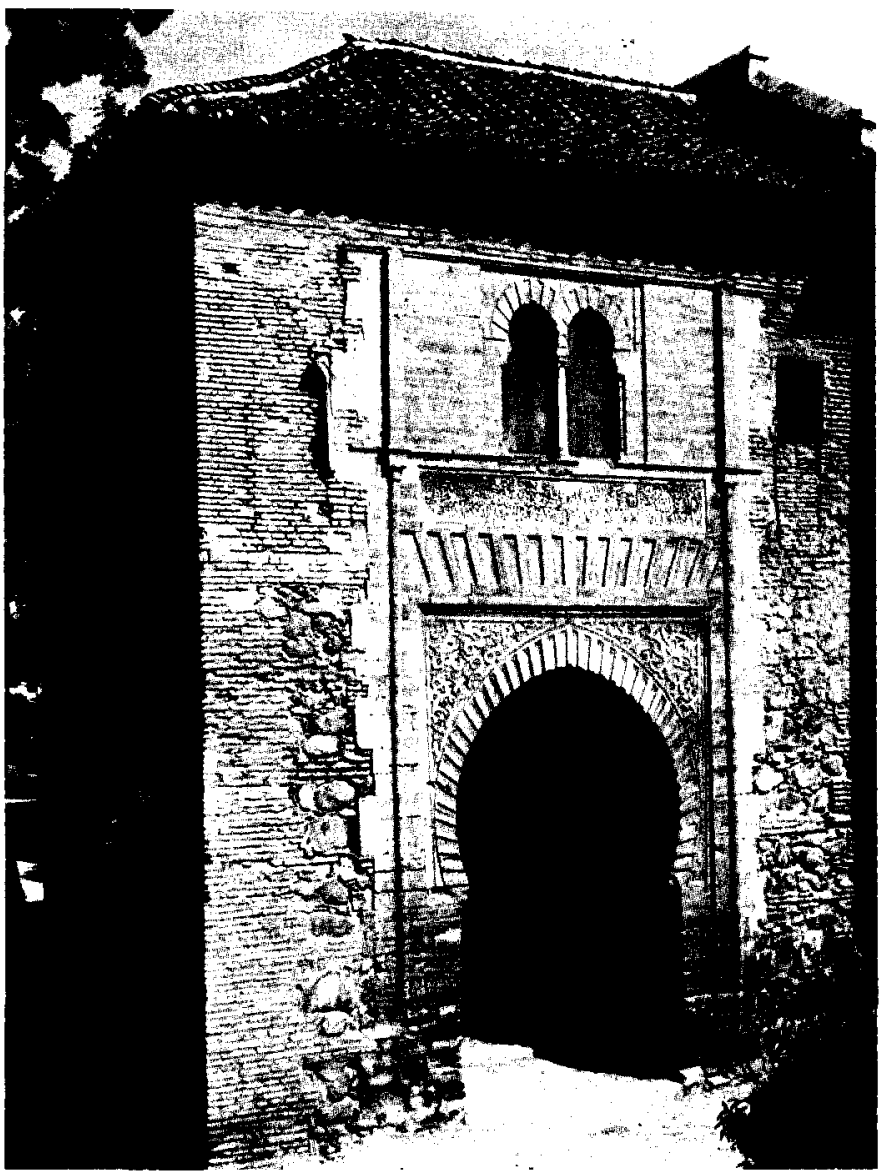

Fig. 4. Puerta del Vino de la Alhambra de Granada.

Consiguientemente, y dado que no conocemos otros constructores que trabajasen en la Alhambra en este periodo, sería difícil negar la probabilidad de que los elementos ziríes de la Alhambra, tanto de la Alcazaba como de otras partes, pertenezcan a las construcciones de ibn Nagrella.

Aparte del recinto de la actual Alcazaba de la Alhambra se detectan obras ziríes en la zona residencial denominada «Palacio de la Alhambra». Así la Puerta del Vino forma parte de una muralla aparecida en las excavaciones del recinto, que unía esta Puerta con la Torre de Machuca conformando este espacio otras torres como la de los Picos y la de Comares. En conjunto todos estos datos parecen indicarnos que las cons- 
trucciones de Yehosef ibn Nagrella debieron emplazarse en la alcazaba y en el Palacio de la Alhambra área eminentemente palaciega, separados de la anterior probablemente por una muralla y puertas interiores.

Existen, además, otros restos dentro de la actual Alhambra más antiguos que las construcciones de los siglos XIV y $\mathrm{xV}$ :

- dos capiteles idénticos situados a la entrada del Cuarto dorado en la antigua Casa Real que Torres Balbás ${ }^{11}$, considera de tradición almohade. Existe un compañero de estos capiteles en el mihrab de la mezquita almorávide de Tremecén, datada en 1135,

- igualmente, dos capiteles de mármol negro que fueron aprovechados en el Patio del harén perteneciente al siglo XIV,

- otros capiteles del tipo llamado de "nido de abeja», que se conservan en el Museo de la Alhambra proceden de su recinto y poseen fuertes influencias califales,

- algunos aleros de la Torre de las Damas de la Alhambra, conservados en el Museo de la Alhambra y que fueron anteriormente adscritos, por razones estilísticas al siglo XII (puesto que aparece el mismo estilo en la Mezquita de Tremecén), son estilísticamente más antiguos. EI motivo de estos aleros, probablemente pasó a esta Mezquita por medio de los artesanos que se sabe habían sido invitados a trabajar en el Norte de África, en Tremecén y Tinmel. Esta descripción sin embargo no comporta necesariamente que estos aleros pertenezcan a una época que sea bastante anterior al 1135. Por naturaleza los artesanos de madera son notoriamente conservadores, lo cual puede explicar el preservar las características estilísticamente antiguas.

Hay que mencionar la «pila de Badis ibn Habbus» en conexión con los restos reaprovechados en la Alhambra. Esta pila, una artesa para agua, perteneciente al tipo de sarcófago, está ricamente decorada por sus lados con figuras de alto relieve de cuatro animales con largos cuernos, cada uno atacado por un león. La pila lleva una inscripción dispuesta sobre otra más antigua, y ella misma en parte superpuesta por otra más tardía. La primera parte de la inscripción dice:

Badis ibn Habbus as-sinh y (había transportado) todas piezas de mármol (?) al castillo de su capital (?) Granada, que Dios le proteja ${ }^{12}$.

El resto de la inscripción se refiere a un gobernante posterior, Muhammad III, y lleva una fecha que equivale al 25 de mayo de 1305.

Torres Balbas, L. en Ars Hispaniae, IV, págs. 98 y 94, fig. 82.
Bargebuhr, Frederick P., op. cit., pág. 184. 


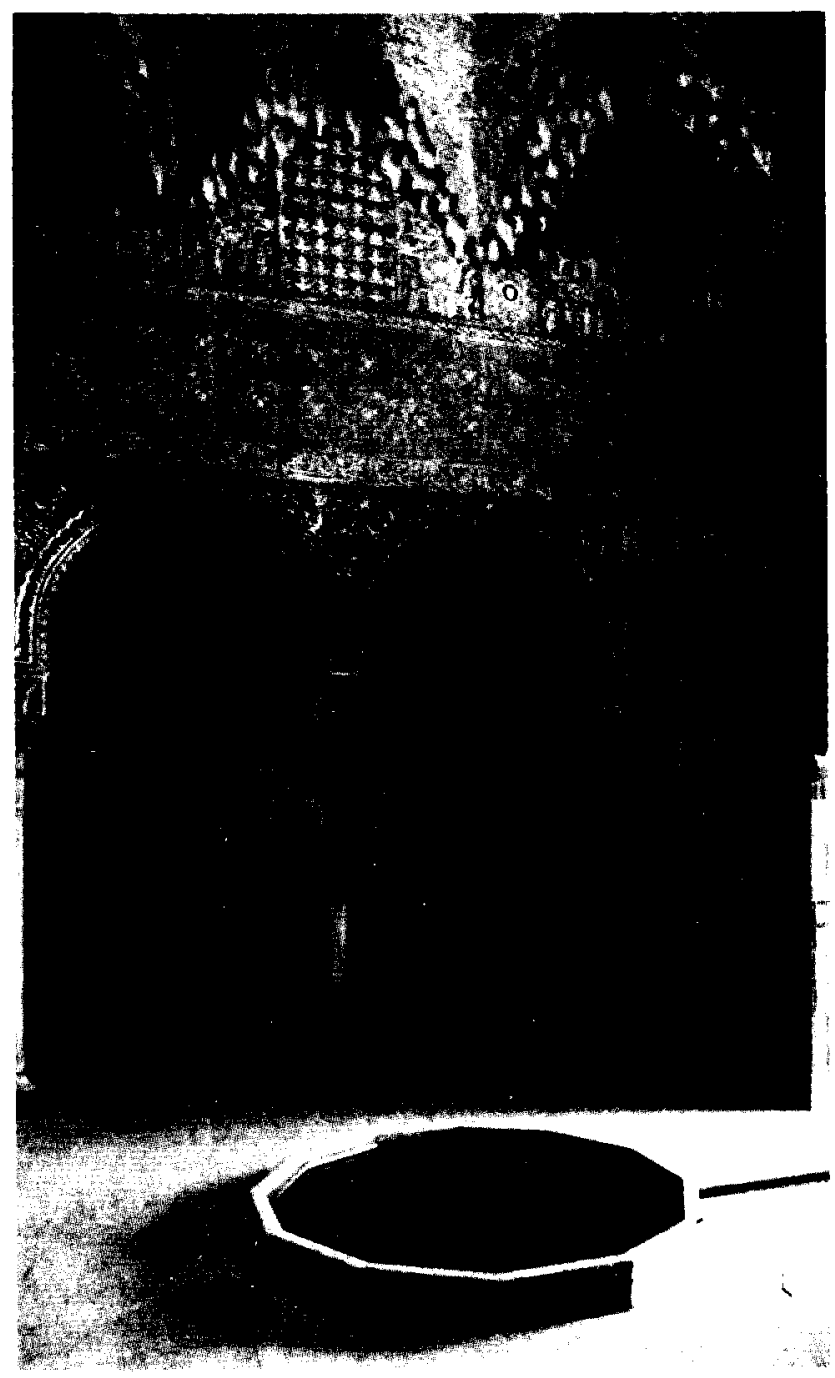

Fig. 5. Sala de los Abencerrajes. Taza de la fuente procedente del antiguo palacio judio de Ibn Nagrella. 
Por lo que se refiere a la fuente con leones mencionada en el poema, vemos como estudiosos actuales ${ }^{13}$ del arte musulmán aceptan su origen en la construcción de Yehosef ibn Nagrella y la remontan por tanto al siglo XI. El poema de ibn Gabirol menciona elementos arquitectónicos de tal palacio antiguo. Concretamente destacamos la descripción que se hace en los dísticos 12-14 de la bóveda de tal palacio:

La bóveda se asemeja al Palanquín de Salomón pendido sobre las glorias de las cámaras.

Que de vueltas en su rotación, brillando semejante a ópalos y zafiros y perlas:

Tal es durante el dia, mientras que en la oscuridad aparece semejante al cielo cuyas estrellas forman constelaciones;

\section{Evidentemente es una influencia clara de Bizancio.}

La idea de construcciones cubiertas con una cúpula rotatoria es muy antigua; reyes de Babilonia erigieron una réplica de la sede del trono celeste de Marduk para simbolizar que ellos mismos lo eran en la tierra, y para manipular el universo por medio de magia simpática. Hay autores que afirman que se puede seguir el rastro de la trasmisión de tales ideas desde el Oriente Próximo a Roma, donde la Domus Aurea de Nerón parece que tuvo un salón giratorio. El modelo más cercano pudo estar en el palacio construido por Abderramán III en Madinat al-Zahra del que se decia que este majlis giraba y se orientaba hacia el sol.

En diversos poemas del diwán de Samuel ibn Nagrella recopilados por su hijo Yehosef, quien puso además diversas notas introductorias a los

13 Gómez Moreno, Ma Elena, La Alhambra, pág. 143. I Jornadas de Cultura Islámica. AlAndalus, OCHO SIGLOS DE HISTORIA. TOLEDO, 1987. Madrid 1989: “Mención especial merece la fuente que da nombre al patio. Sus doce leones acusan técnicas y estilo en todo ajenos a la época nazarí; por el contrario resultan cercanos a cosas califales. La taza, con sus adornos y el poema que se desarrolla en torno, laudatorio del sultán Muhammad $V$, está sin duda montada sobre unos leones muy anteriores. En efecto: en la Sala de Abencerrajes hay una fuente de mármol, desproporcionadamente grande, de forma poligonal de doce lados, que se corresponde con los leones y que es sin duda, su taza primitiva. Los más recientes estudios permiten suponer que taza y leones pueden proceder del Palacio de Samuel-ibn-Nagrella, personaje judío ministro del rey zihri Habús y perteneciente a aquella sociedad judía numerosa y culta de la Granada del siglo xı. Se conoce una poesía en alabanza de Ibn Nagrella, en que se cita su magnifico palacio en la Alhambra y en él, una fuente con doce leones. La fuente, por tanto, pudo ser la de abluciones rituales del oratorio de Ibn Nagrella, a altura propicia y con los doce leones simbólicos. Esto aclara el estilo de los leones al situarlos en los primeros decenios del siglo Xi. 
distintos poemas, encontramos testimonio de otras construcciones llevadas a cabo particularmente por Yehosef ibn Nagrella, para el palacio de su padre (no para el de Yehosef en la Alhambra).

Uno de tales poemas tiene una introdución del siguiente tenor:

"Yo Yehosef planté unos retazos de césped de forma redondeada y lo rodeé con un canal circular de agua. Tras ello sugerí a él [a Samuel] que diese un paseo hasta el lugar para descansar allí; él improvisó:» ${ }^{14}$.

Sigue el poema de Samuel a este jardín obra de Yehosef describiendo sus excelencias. Para Bargebuhr esto apoya la tesis que demuestra que ya en su juventud había desarrollado Yehosef una inclinación hacia la arquitectura paisajística. El padre volviendo a casa probablemente de una misión guerrera o diplomática, se encuentra con la sorpresa de un nuevo "buen retiro" diseñado por su hijo. Las palabras por las que comienza el poema del padre se refieren a un jovencito que cautiva a su encantado padre quien adora a su hijo. En el mismo poema se nos indica un simbolismo de tal jardín: el prado circular rodeado por el canal de agua es una réplica metafísica de la tierra rodeada por el cielo.

Con todo ello Yehosef no era sino el heredero de la predilección de origen cordobés por parte de su padre hacia una arquitectura de cuento de hadas. El mismo Samuel ha-Nagid nos atestigua sus propios experimentos sobre los efectos de agua y luz, llevados a cabo por medio de artefactos de la época, en sus descripciones en versos hebreos. Uno de los poemas está prologado con las siguientes notas escritas por Yehosef:

«Este poema describe una fuente que estaba en su casa: desde la parte superior salía agua que caía en forma de una cúpula sobre un suelo de alabastro y mármol; se habian colocado luces dentro de tal "cúpula" que, de tal forma quedaban cubiertas por ella también había una lámpara de cera en la parte superior" ${ }^{15}$.

Otro poema a una fuente tiene la siguiente introducción:

«El también compuso la descripción de una vasija que esparcía agua en forma de aspersión; en la parte exterior del tal vasija sobresalian unos tubos que arrojaban el agua en todas las direcciones posibles ${ }^{16}$.

14

15

16

Bargebuhr, Frederick P., op. cit., pág. 141.

BaRgebuhr, Frederick P., op. cit., pág. 140-145.

BARgEBUhR, Frederick P., op. cit., pág. 140-145. 
También se encuentra un tercer poema que tiene como finalidad la descripción de un objeto artístico y que es prologado así: «Esta es la descripción de un 'brasero, delante de él, ardiendo en los días de invierno" (Jer 36,22$)$, alrededor del cual fueron colocadas estatuas de pájaros»" ${ }^{17}$.

Tales montajes experimentales de agua y luz, afines a construcciones bizantinas, pertenecen a una tendencia de la arquitectura cortesana de la época. Así Yahya ibn Ismail al Mamun, rey de Toledo (1043-1075), levantó su pabellón de cristal hacia el final de su vida como nos refiere al-Maqqari (por ello tal pabellón difícilmente puede haber sido el modelo para la obra de Samuel que murió en 1056).

Parece, por todo ello, que la villa de Samuel ha-Nagid que probablemente estuvo situada en el barrio judío de Granada, desplegaba efectos de agua y luz en su jardín y patio, que, de alguna manera, anticiparon aquellos de la Alhambra de Yehosef. Por supuesto que tales estatuillas de animales y fuentes iluminadas no son comparables a la Fuente de los Leones, ni los patios con estatuas o la construcción elaborada de la cúpula del palacio de la Alhambra, pero la idea gérmen está presente aquí.

Otro de los grandes palacios de un relevante judío conocido y citado constantemente en leyendas y por la historiografía posterior es el ocupado por Samuel Leví Abulafia, tesorero de Pedro I de Castilla y constructor de la Sinagoga de su nombre, popularmente conocida como del Tránsito, en cuyas cercanías estaría emplazada su residencia cuyas referencias son aun más imprecisas y generales si cabe que las del construido en Granada, y casi siempre se trata de alusiones indirectas con motivo de otro asunto. Las noticias más abundantes y fiables nos las proporcionan las fuentes narrativas, en tanto que la arqueología no ha facilitado aún dato o resto alguno que pueda ser atribuido con certeza al palacio del tesorero regio. Finalmente, las fuentes literarias que tan generosamente se ocupan del palacio de Yehosef ibn Nagrella, nada nos cuentan sobre las excelencias del palacio toledano.

El palacio que Samuel Leví ocupa en la ciudad de Toledo aparece mencionado por vez primera en las fuentes narrativas en 1354 con motivo de la entrada en él del maestre de la Orden de Santiago, don Fadrique, hermano bastardo de Pedro l, alineado en el bando trastamarista para cuya causa logró apoderarse de los tesoros del reino guardados en «las casas de don Simuel el Levi» ${ }^{18}$.

Bargebuhr, Frederick P., op. cit., pág. 143.

18 López de Ayala, P., “Crónica” año V, cap. xxVIII, pág. 452.. 


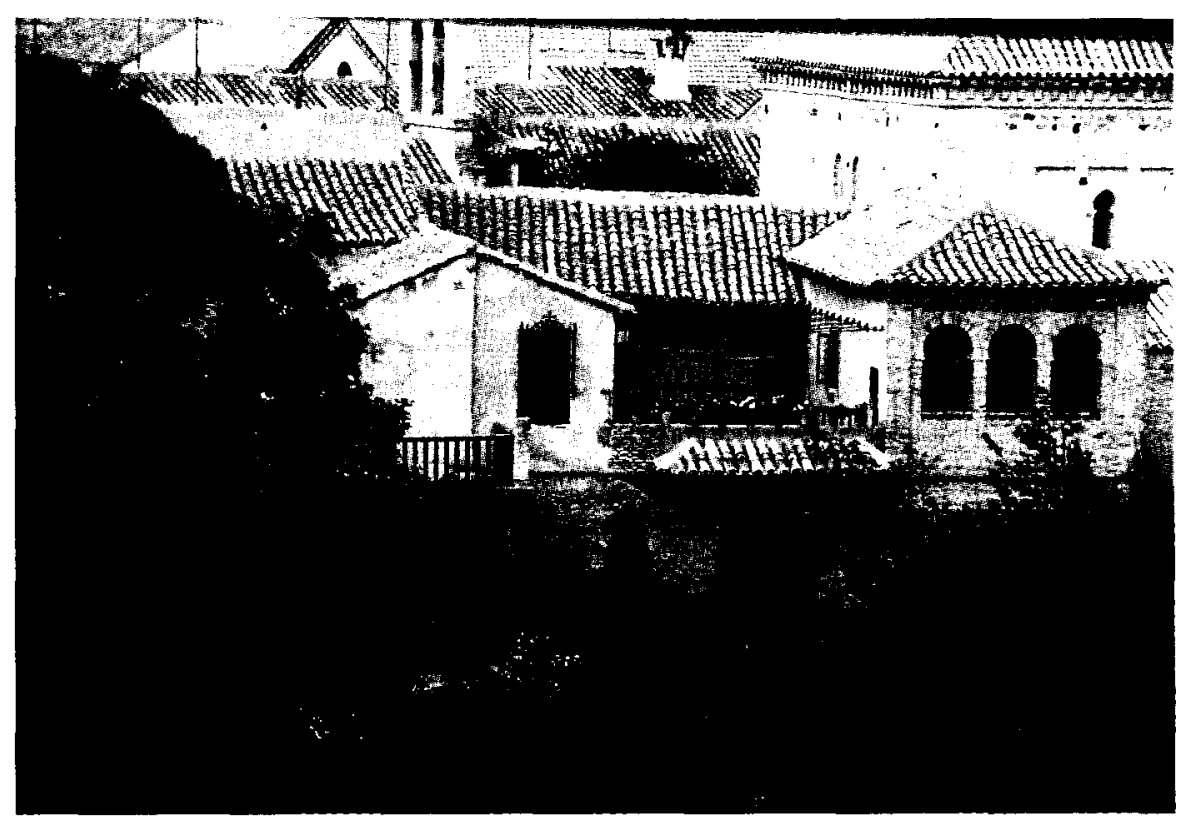

Fig. 6. Vista de la Casa-Museo del Greco, en la juderia de Toledo.

Este fue uno de los reveses que impulsó al monarca a acudir al encuentro de Toro a tratar con los conjurados. La situación de la Hacienda Real atravesaba momentos tan críticos que fue preciso tras cinco años al frente de la misma, que Samuel Leví acometiese su reorganización. Queda bien reflejada esta necesidad en el pasaje de la Crónica cuando Pedro I jugando a los dados en la aldea de Morales cercana a Toro, de donde había escapado en diciembre del año anterior, se queja de lo menguado de su tesoro, por lo que su Tesorero Mayor para subsanar tal carencia, le pide ampliación de sus poderes fiscales a fin de evitar que sus recaudadores se atrevieran a hacer cosas que no debían, al amparo de la confusión existente en el reino y de la juventud del rey, sin que don Samuel les pudiera tomar en cuenta. A continuación solicita del rey la concesión de dos castillos pidiendo el alcázar de Trujillo y el castillo de Hita para poner en ellos tesoros ${ }^{19}$.

Traza así el eje Hita-Toledo-Trujillo donde situa el corazón de la recuperación financiera del reino, logrando descentralizar el tesoro de la 
corona, no asi su gestión, para dificultar un despojo como el protagonizado por don Fadrique. Asímismo, la proximidad a Toledo permitía a don Samuel controlar estrechamente los ingresos de los otros dos emplazamientos hacendísticos, situando a su frente a oficiales de entera confianza. En Trujillo pone a Martín Martínez y en Hita a Juan Díaz de llescas «su recabdador” y miembro de sus casas ${ }^{20}$. En el plazo de un año logró albergar "muy grand algo" en las dos fortalezas citadas. En lo sucesivo encomendó públicamente la recaudación de las rentas de la corona a sus parientes y allegados para evitar retrasos o distracciones de ingresos, actuando éstos con eficacia y honradez tal que tras la caída del Tesorero real no se pudo actuar contra ellos.

En la segunda mitad del año 1360 , se produjo insesperadamente la caída en desgracia del poderoso tesorero. En un documento dado en Sevilla el 13 de diciembre de 1360 , Pedrol comunica a los justicias de Toledo y de su arzobispado que había mandado tomar los bienes de su tesorero Samuel Leví y de sus familiares, por deudas de las rentas reales, ordenando que se vendan sus bienes y se entregue su valor a Tel Fernánde ${ }^{21}$, mencionado en otro documento de 1366 como alcalde mayor de Toledo que habita en las casas que el rey tiene en la judería uen un palacio que es en ellas do toman las cuentas del dicho sennor rey, los sus contadores, et estando y presentes el dicho Tel Ferrandez..." encontraron en un arca un libro de cuentas donde se inserta una carta de pago de $257.000 \mathrm{mrs}$. librada por Samuel Leví el 3 de diciembre de 1358 a favor de doña Marina ${ }^{22}$.

Otro documento de abril de 1366 dice que los escribanos de Toledo atestiguan que "estando en las casas del rey que hay en la judería de Toledo, que fueron morada de don Simuel el Levím ${ }^{23}$, se leyó una carta del rey ordenando que Tel Fernández entregue al abad de Husillos, su hijo, el libro rosario que fue del arzobispo de Toledo don Vasco. En estos

20 En un documento del 13 de mayo de 1360 el alcalde de Alcalá atendiendo a las cartas presentadas por poder de Juan Díaz de Illescas procede a vender unos bienes en subasta. Se inserta carta del rey para que se pague a Johan Díaz de Illescas, criado de don Samuel el Leví (León TELLo, P., Judíos de Toledo, vol. II, n533, pág. 149). [Queremos destacar como en este documento el recaudador Juan Díaz de Illescas que hacía ya varios años que había sido puesto al frente de Hita, aparece ejerciendo sus funciones en Alcalá, lo que permite suponer que esta fortaleza y la de Trujillo tendrían asignada un área espacial de actuación específica. Desde Toledo se coordinarian actuaciones y Samuel Leví intervendría directamente en los bienes reales de la ciudad y su comarca, además de en el resto del reino].

21 Lé́n Tello, P., "Judíos...», op. cit.,... vol. II, n 535, pág. 150.

22 Ibidem, n 547, pág. 153.

23 Ibidem, n548, pág. 153. 


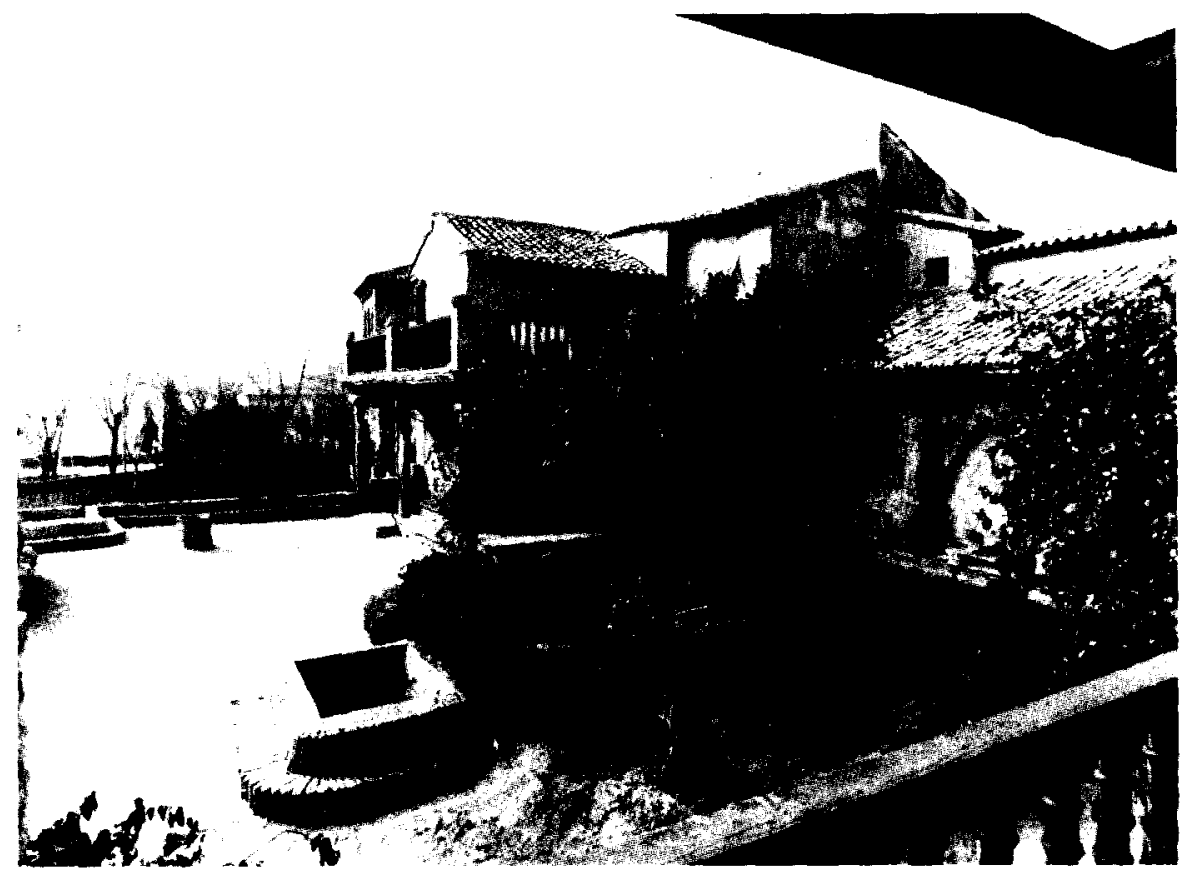

Fig. 7. Casa-Museo del Greco, jardines altos. Bajo ellos se encuentran dos niveles de sótanos.

interesantísimos documentos se trasluce que las casas ocupadas por Samuel Levi eran un conjunto de dependencias residenciales pertenecientes al rey. A la muerte del Tesorero, tras su confiscación, luego sirven de vivienda al alcalde mayor de Toledo. En ellas destaca un área especial destinada a funciones administrativas, propias del oficio de quien las habitara, siendo el espacio más relevante de este sector el denominado en la documentación "palacio" donde se llevan las cuentas del rey y se guardan los documentos contables en arcas, es decir, en esta sala principal estaría parte del archivo de la Hacienda regia, celosamente conservado. Dicho espacio en 1366, con su nuevo ocupante Tell Fernández, sigue manteniendo el antiguo uso dado por Samuel Leví.

Las riquezas recaudadas por Samuel Leví se guardarian en otras estancias de la zona administrativa, que probablemente nada tendrían que ver con los sótanos de la Casa del Greco, inadecuados para una función de estas características. En su casa se encontraron tras ser apresado, 160.000 doblas, 4.000 marcos de plata, 125 arcas de paños de oro y seda y otras joyas, además de 80 moros, moras y moreznos esclavos a su 


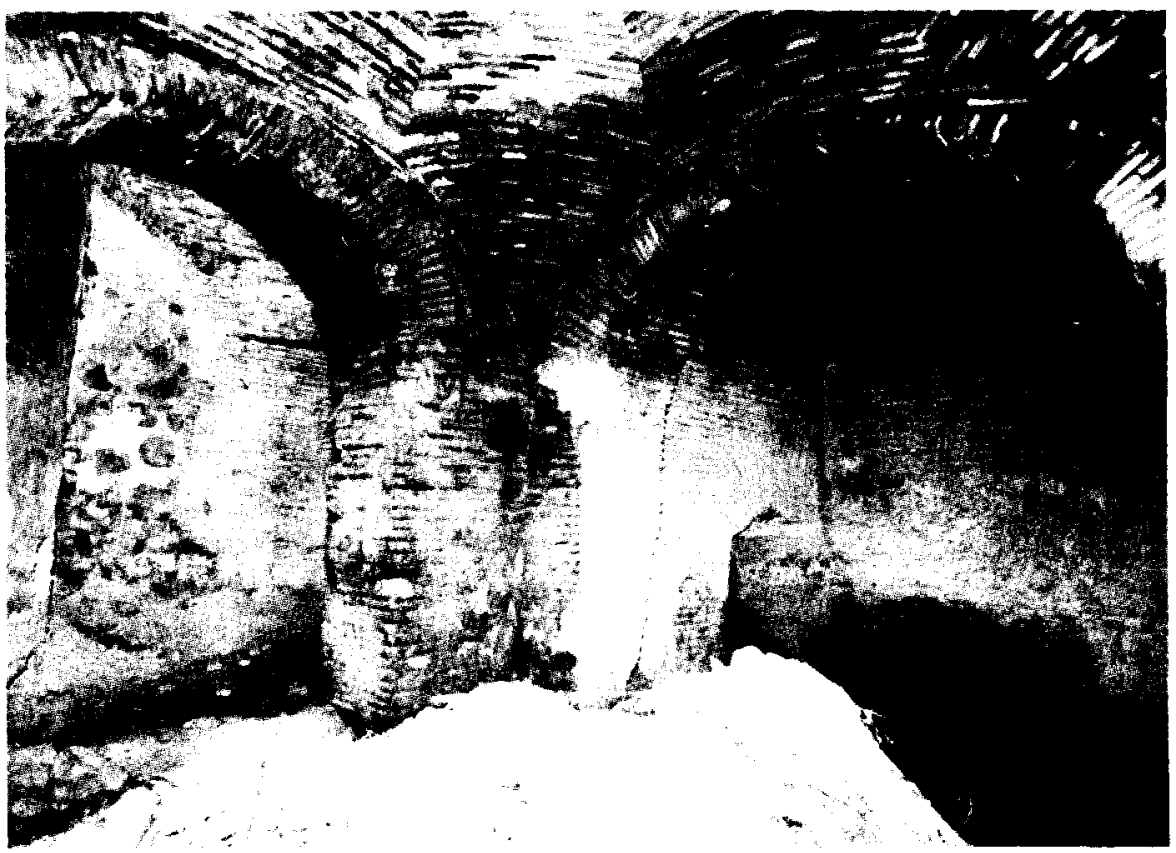

Fig. 8. Segundo nivel de los sótanos. Sala con la piscina de la miqvé al fondo.

servicio, cuyo elevado número nos hace sospechar que no sólo se les asignarían actividades domésticas sino que también participarían en la protección y custodia de ese patrimonio.

Parece evidente que el solar de las casas, que no palacio, del Marqués de Villena, sería lo suficientemente extenso como para integrar estos antiguos sótanos, anteriores al menos en el nivel más bajo al siglo xv por 10 que estarían en pie o serían edificados en parte en tiempos de Samuel Leví. Esta opinión se ve reforzada por el hallazgo en el piso inferior de una miqvé o baño ritual judio ${ }^{24}$, en una sala cuya cúpula posee claraboyas

24 López Álvarez, Ana Maria y Palomero Plaza, Santiago, “Descubrimiento de un probable baño ritual junto a la Sinagoga del Tránsito", Sefarad, XLIX (1989) 2, págs. 395-398. LóPEZ ÁLvarez, Ana María y Palomero Plaza, Santiago, Ciencia y sociedad "Baño ritual Judío", Investigación y ciencia, enero (1990), págs. 36-38. Palomero PlazA, Santiago, López Álvarez, Ana María, Alvarez Delgado, Yasmina, “Excavations in the Samuel Halevi Abulafia (Nuestra Señora del Tránsito) Synagogue in Toledo", Jewish Art: Sepharad, vol. 18 (1992). 


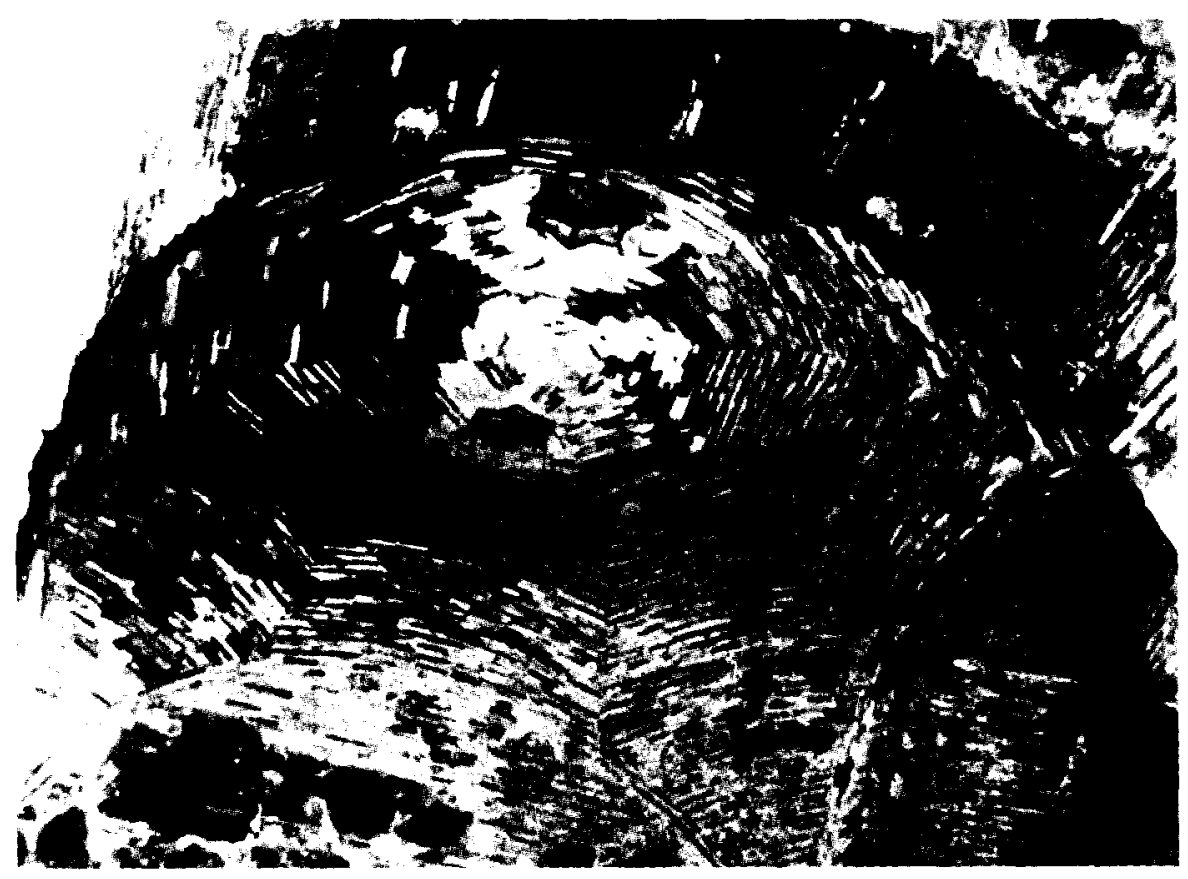

Fig. 9. Cúpula de la miqvé con las claraboyas estrelladas.

de forma estrellada dentro de la más pura tradición constructiva islámica para aportar luz y ventilación a este espacio, por lo que son respetadas cuando se edifica el nivel superior de los sótanos formando parte del suelo del nuevo piso pero sin cegarlas puesto que la estancia que iluminaban seguiría en uso y por tanto el baño ritual que la da sentido. 